\title{
The operational and laboratory aspects of a thin spray-on liner
}

\author{
PK Boeg-Jensen Luossavaara-Kiirunavaara $A B$, Sweden
}

G Swan Rock Mechanics \& Mine Design, Canada

\begin{abstract}
Bolts, shotcrete and mesh are today a part of the standard ground support system, although it becomes economically challenging to combine them sufficiently to support seismically active ground that requires increased yielding and energy-absorbing capabilities. An enhancement to current ground support systems is the thin spray-on liner (TSL) that may possess significant yielding properties. TSL has the potential ability to support seismically active ground in terms of deformation and rock bursting, common in deep mining.

This paper describes part of an investigation, to prove whether the current formulation of a TSL called $3 M$ polymeric composite membrane (PCM) could be implemented as an alternative ground support system or for improvement of the support capabilities for application in complex ground types. The paper delivers some conclusive operational and laboratory results that are expected to achieve this.

The trials examined the operational and laboratory aspects of the TSL. The paper focuses on the specific operational testing conducted at the Nickel Rim South Mine during 2012, together with the re-testing at MTI experimental mine and CANMET laboratory in 2013 that provided additional evidence. The health and safety aspects of TSL application are manageable due to robotic application and temporary shutting down of the local ventilation to prevent the dispersion of isocyanates. The test results available for the full composite liner material concluded that peel off at the leading edge next to the face blast, together with fly-rock damage, was severe, due to primer adhesion failure and insufficient curing time, so this result was therefore considered to be a failure. The same test was performed on topcoat only, with significant improvement. The robot managed to apply the TSL with sufficient coverage and consistent thickness on the walls, except for the edges where the guns flip over and missed large perimeter patches, which was not dealt with till later in the testing. $3 \mathrm{M}$ took the effort back to the lab and produced three adhesive primers, while Asea Brown Boveri (ABB) refined the robotic application controls. Re-testing was completed in August and September 2013.
\end{abstract}

These results indicate the requirement of a rehab procedure for damage caused to the liner. In addition, bolting of the leading edge could be implemented to partially address the peeling issue. Liner adhesion failure may occur due to rock failure however the liner retains the loose material. The trial was done only on the rock walls; in order to make a fair judgment on the liner performance and capability it should in addition be applied on the shoulders and the back. Full proof of operational liner functionality requires underground deployment of a prototype mobile carrier.

\section{Introduction}

The invention and development of a liner with high yielding and energy absorbing capacities through its high tensile strength has taken about 25 years and is referred to generically as a thin spray-on liner or TSL. The subject of this paper is a particular type of TSL developed by 3M Canada in the form of a two part PCM comprising of a primer and a tough polymer topcoat.

This liner, called the 3M PCM, was developed to provide a TSL product with superior tensile and elongation characteristics for gravity or moderate stress-driven local loose failure with further consideration for other scenarios. Conceptually, the preferred TSL should obtain reinforcement and retaining function superior to either fibre reinforced shotcrete and/or mesh under highly deformable and rockbursting ground conditions. 
The paper aims to present some of the conclusive operational evidence and laboratory results, required to prove the TSL as a feasible component in underground rock support.

The paper focuses on work completed from January 2012 until September 2013 and summarises the operational and laboratory testing in Sudbury. The operational trials were executed at Nickel Rim South (NRS) Mine, with additional laboratory re-testing at Mining Technology International (MTI) and CANMET, the Federal Canadian mining research agency. The 3M PCM project is mainly funded by CAMIRO's Deep Mining Research Consortium (DMRC), a collaborative research programme funded by Vale, Glencore, Rio Tinto, Barrick, Agnico-Eagle and the Northern Ontario Heritage Fund Corporation.

\title{
$2 \quad$ Thin spray-on liners
}

Based on nearly 25 years of experience with TSLS much has been learnt about its performance and properties, which are essential in achieving the final product that provides the desired strength, toughness, adhesion and elasticity for reinforcement within mining applications (Swan 2014).

According to Boeg-Jensen (2013) the original strategy was to apply two layers when spraying the material, since it was a two layer composite system. The application was automated. First a thin primer to promote adhesion was sprayed on a cleaned and prepared rock surface, allowing the main topcoat to mobilise its key physical properties such as tensile strength, elongation and toughness as the load is generated due to eventual loose rock failure. The topcoat is preferably 3-4 $\mathrm{mm}$ thick and comprised of a hybrid polyurea chemistry, known for its high tensile strength and toughness. In order to form an adequate ground support, the liner requires support by a standard bolting pattern as with shotcrete and mesh. The basic functions of the 3M PCM and its installation are demonstrated in Figure 1.

According to Swan (2014), 3M's original TSL system was designed to use a foam-based primer that was meant to adhere to damp surfaces to create a smooth surface, filling in gaps or cracks. However it was concluded that the primer provided poor adhesion and was too soft to resist blast fly-rock damage. After an initial review, a system was selected, a topcoat with optional adhesive promoting primer system.

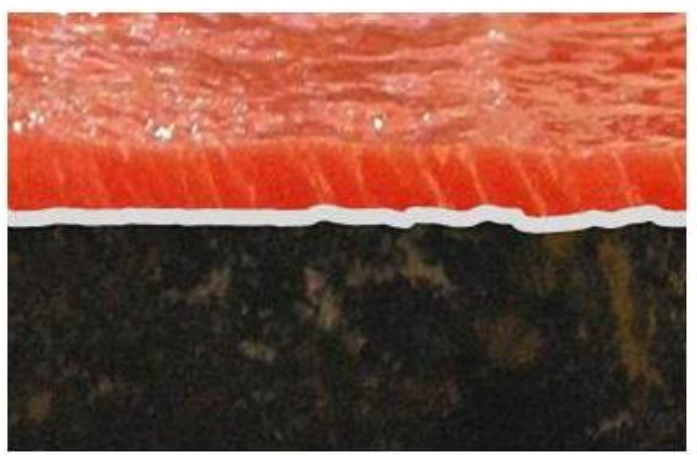

\section{3-4mm PCM topcoat}

$<1 \mathrm{~mm}$ optional adhesive promoting primer

\author{
Rock or shotcrete
}

Figure 1 3M's PCM system (Swan 2014)

\section{Methodology}

Operational and laboratory-based test trials were performed in Sudbury between January 2012 and September 2013. The operational trials were executed at Nickel Rim South Mine at 1,565 m level, laboratory testing was completed at CANMET's Sudbury laboratory and additional operational re-testing was done at the MTI adit facility, without the production disturbances. The aim of the trials was to simulate the most critical mining environment in terms of contact zones, cracks, high stresses with high possibility of rockbursts and large deformation zones. In total the five trials presented in this paper, and performed at CANMET, Nickel Rim South Mine and MTI, are summarised in Table 1. 
Table 1 Trial purpose and methodology

\begin{tabular}{|c|c|c|}
\hline Trial & Purpose & Methodology \\
\hline $\begin{array}{l}\text { Isocyanates } \\
\text { Nickel Rim South Mine }\end{array}$ & $\begin{array}{l}\text { Measure the isocyanate } \\
\text { concentration for validation } \\
\text { under the health and safety } \\
\text { regulations. }\end{array}$ & $\begin{array}{l}\text { The concentrations are measured before, } \\
\text { during and after application at different } \\
\text { distances from the working area. }\end{array}$ \\
\hline $\begin{array}{l}\text { In-cycle blasting } \\
\text { Nickel Rim South Mine }\end{array}$ & $\begin{array}{l}\text { Define the adhesion and } \\
\text { toughness of } 3 \mathrm{M} \mathrm{PCM} \text { due to } \\
\text { in cycle blasting. }\end{array}$ & $\begin{array}{l}\text { Three alternative were tested, the full } \\
\text { composite with primer and } 4 \mathrm{~mm} \text { topcoat, } \\
4 \mathrm{~mm} \text { topcoat only and } 8 \mathrm{~mm} \text { topcoat only. }\end{array}$ \\
\hline $\begin{array}{l}\text { Robotics } \\
\text { Nickel Rim South Mine }\end{array}$ & $\begin{array}{l}\text { Identify the quality of } \\
\text { robotic application in terms } \\
\text { of consistency, coverage and } \\
\text { thickness. }\end{array}$ & $\begin{array}{l}\text { Thickness control was performed with an } \\
\text { ultrasonic unit at } 58 \text { randomly picked } \\
\text { points and validated through drilling cores. }\end{array}$ \\
\hline $\begin{array}{l}\text { Large scale pull test } \\
\text { MTI }\end{array}$ & $\begin{array}{l}\text { Control the adhesive and } \\
\text { toughness properties of } 3 \mathrm{M} \\
\text { PCM during application. }\end{array}$ & $\begin{array}{l}\text { A plate was covered with a } 2 \times 2 \mathrm{~m} \text { patch } \\
3 \mathrm{M} \text { PCM and bolts with } 1 \times 1 \mathrm{~m} \text { grid, and } \\
\text { then the plate is pulled into the drift. }\end{array}$ \\
\hline $\begin{array}{l}\text { Round determinate } \\
\text { panel } \\
\text { CANMET }\end{array}$ & $\begin{array}{l}\text { Determine } 3 \mathrm{M} \text { PCM } \\
\text { toughness. }\end{array}$ & $\begin{array}{l}\text { A circular disk of cast fibre reinforced } \\
\text { shotcrete was placed onto three rigid } \\
\text { points and a ram loads the shotcrete at its } \\
\text { centre. The disk was covered with different } \\
\text { compositions of the } 3 \mathrm{M} \text { PCM to determine } \\
\text { its reinforcing capacities. }\end{array}$ \\
\hline
\end{tabular}

\section{$4 \quad$ Results}

\subsection{Isocyanates}

The isocyanate testing was conducted before, during and after the 3M PCM application. The results show that there are high levels of isocyanates during application in the hot zone or work area, but only $5 \mathrm{~m}$ outside the hot zone the levels are considerably lower and beneath the time weighted average and ceiling limits, as presented in Figure 2. Between 30-60 minutes after application, the isocyanate levels are beneath the time weighted average and ceiling limits both at the hot zone and downstream from the hot zone. This presumes that the ventilation is turned off during application and for 30 minutes after completed application. A water curtain did not decrease the isocyanate levels and was therefore abandoned. With respect to these results a safety protocol was set up, requiring a barricade $20 \mathrm{~m}$ downstream from the hot zone, with no allowance access until 30 minutes after completed application. The safety protocol also requires ventilation to be turned off during application and for 30 minutes after completed application to avoid dispersal of any potential airborne isocyanates (Boeg-Jensen 2013). 


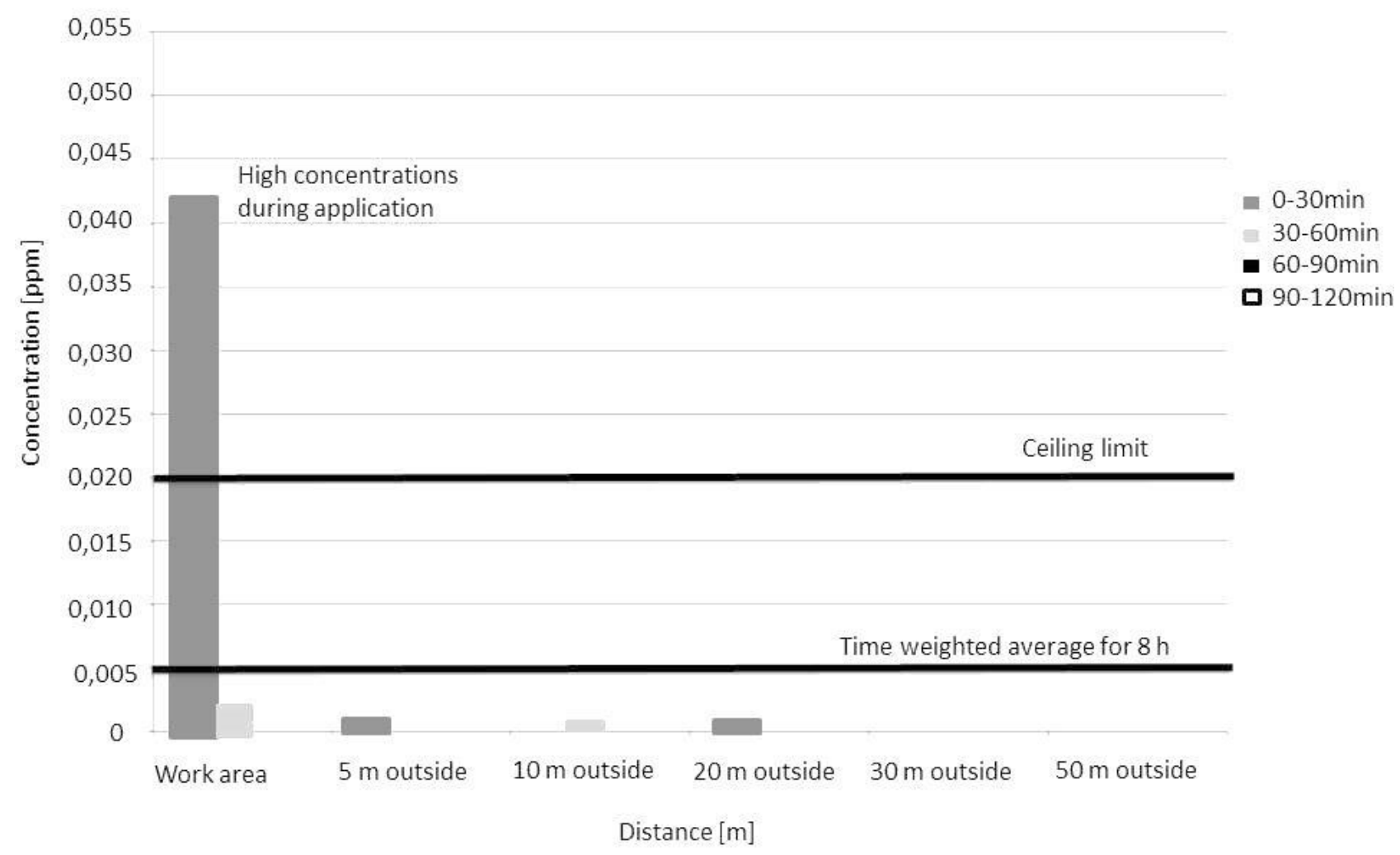

Figure 2 Isocyanate concentrations downstream from the working area and during different time intervals

(Boeg-Jensen 2013)

\subsection{In-cycle blasting}

\subsubsection{Full composite}

The results from the in cycle blasting trials were immediately apparent after the blasted round. The impact from the blasting caused peel back of the full composite at the leading edges and the blast also caught some of the overlaps and peeled them back. Note that the 3M PCM was not bolted right up to the face as would be done with mesh or shotcrete. Furthermore the perimeter areas generally had a lower total thickness application due to the initial spray pattern setup, and the interface between panel applications comprised of top coat/primer/top coat, rather than top coat to top coat resulting in better adhesion. In several cases the face blast also blasted out the wall behind the applied coating. In addition, post-blast observations confirmed of significant fly-rock damage and cracking. Also the mucking-out operation tended to tear pieces of the 3M PCM. The first sprays in this test were using material that was water contaminated which also contributed to the majority of the small cracks. These observations together determined the results a failure from the performance point of view. The observations are illustrated in Figures 3 through 5 , where the fault lines are poorly indicated (Boeg-Jensen 2013). 


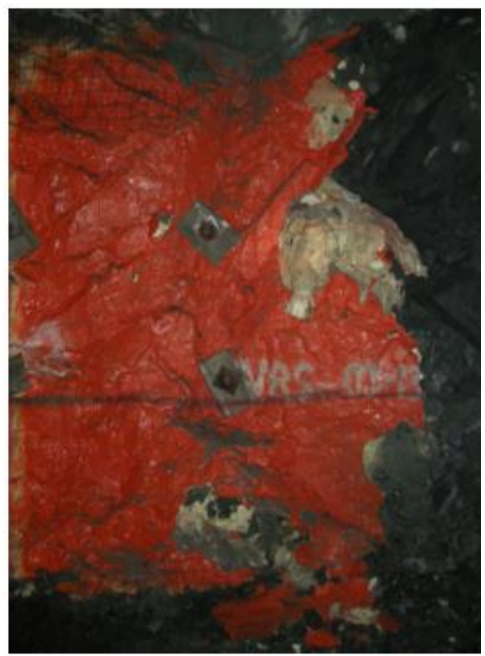

Figure 3 Peel back damage due to blasting of a round for full composite consisting of primer and $4 \mathrm{~mm}$ top coat (Boeg-Jensen 2013)
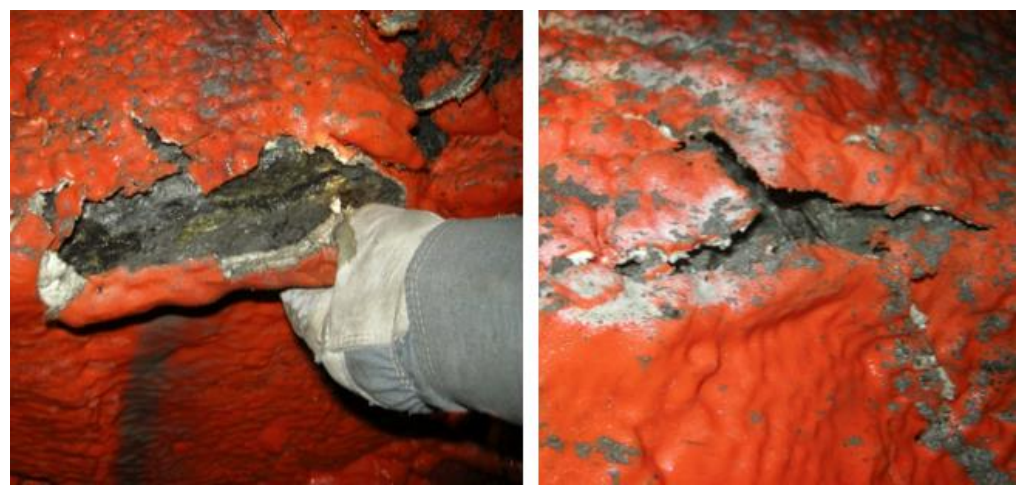

Figure 4 Fly-rock damage in full composite consisting of primer and $4 \mathrm{~mm}$ top coat (BoegJensen 2013)

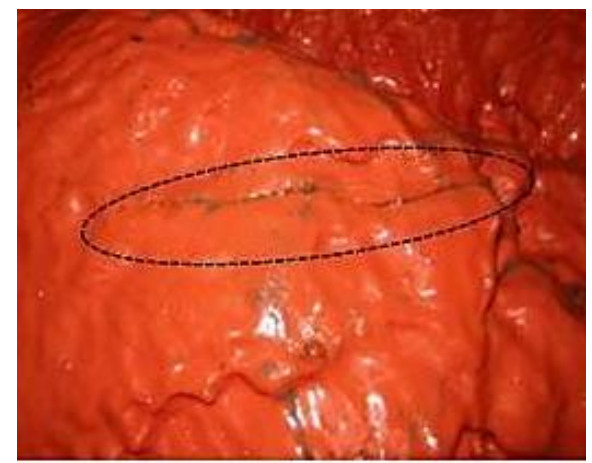

Figure 5 Small crack in full composite consisting of primer and $4 \mathrm{~mm}$ top coat (Boeg- Jensen 2013)

\subsubsection{Top coat only with 4 and $8 \mathrm{~mm}$ thickness}

The same test was repeated without the foam for a 4 and $8 \mathrm{~mm}$ top coat application respectively, with significant improvement. The peel back was reduced as well as the fly-rock damage for both 4 and $8 \mathrm{~mm}$ top coat applications (Figures 6 through 8). Although the $4 \mathrm{~mm}$ application managed to decrease the level of peel back and fly-rock damage compared to the full composite, it did not provide sufficient coverage and experienced gaps. The $8 \mathrm{~mm}$ top coat thickness gave the best results in terms of minimum peel back, 
sufficient coverage, minimum fly-rock damage, and the immediate area surrounding the fly-rock damage did not loosen up (Boeg-Jensen 2013).
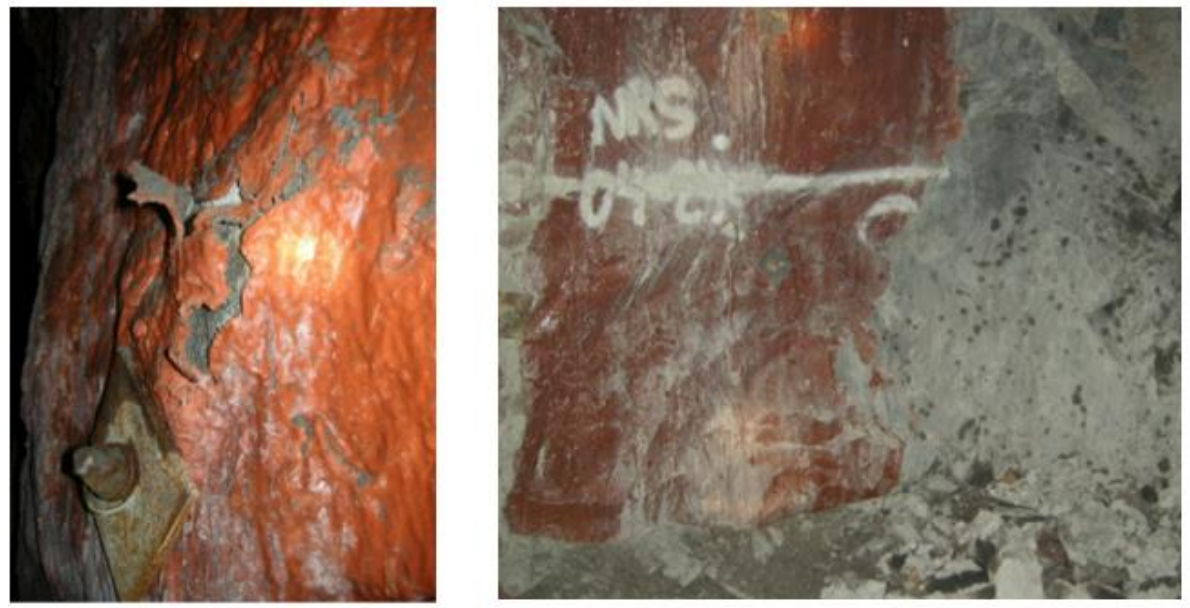

Figure 6 Fly-rock damage to the left, and leading edge to the right, for $4 \mathrm{~mm}$ top coat (BoegJensen 2013)

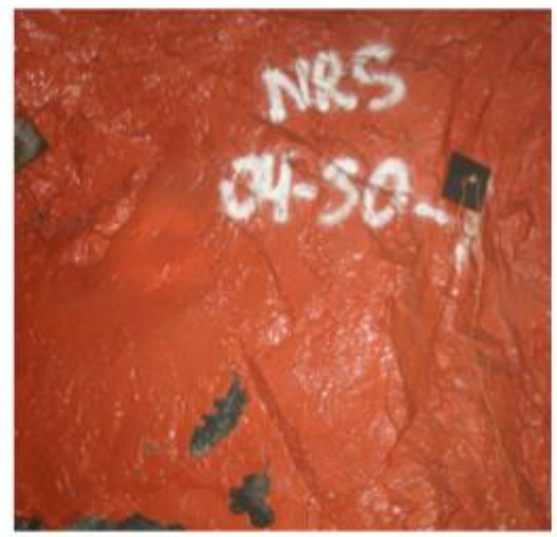

Figure 7 Scoop damage on the lower part of the wall for $8 \mathrm{~mm}$ top coat (Boeg-Jensen 2013)

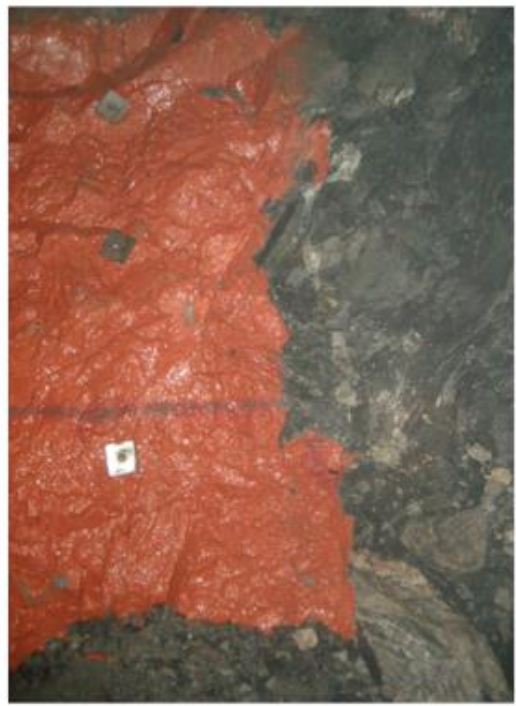

Figure 8 The leading edge after cycle blast for $8 \mathrm{~mm}$ top coat (Boeg-Jensen 2013) 


\subsection{Robotics}

The thickness control and continuity of the liner is of importance to gain sufficient coverage. Targetted thickness measurements were performed during the test trials to assure the quality of robot application and thickness continuity.

The results from the targetted thickness measurements for the top coat are based on a total of 58 points measured for seven different spray applications for the desired thickness of $4 \mathrm{~mm}$. The maximum thickness reached $7.30 \mathrm{~mm}$ and the minimum $1.71 \mathrm{~mm}$ with an average $4.38 \mathrm{~mm}$ and standard deviation $1.11 \mathrm{~mm}$ which shows that there is good consistency for the application thickness. The results are displayed in Figure 9 (Boeg-Jensen 2013).

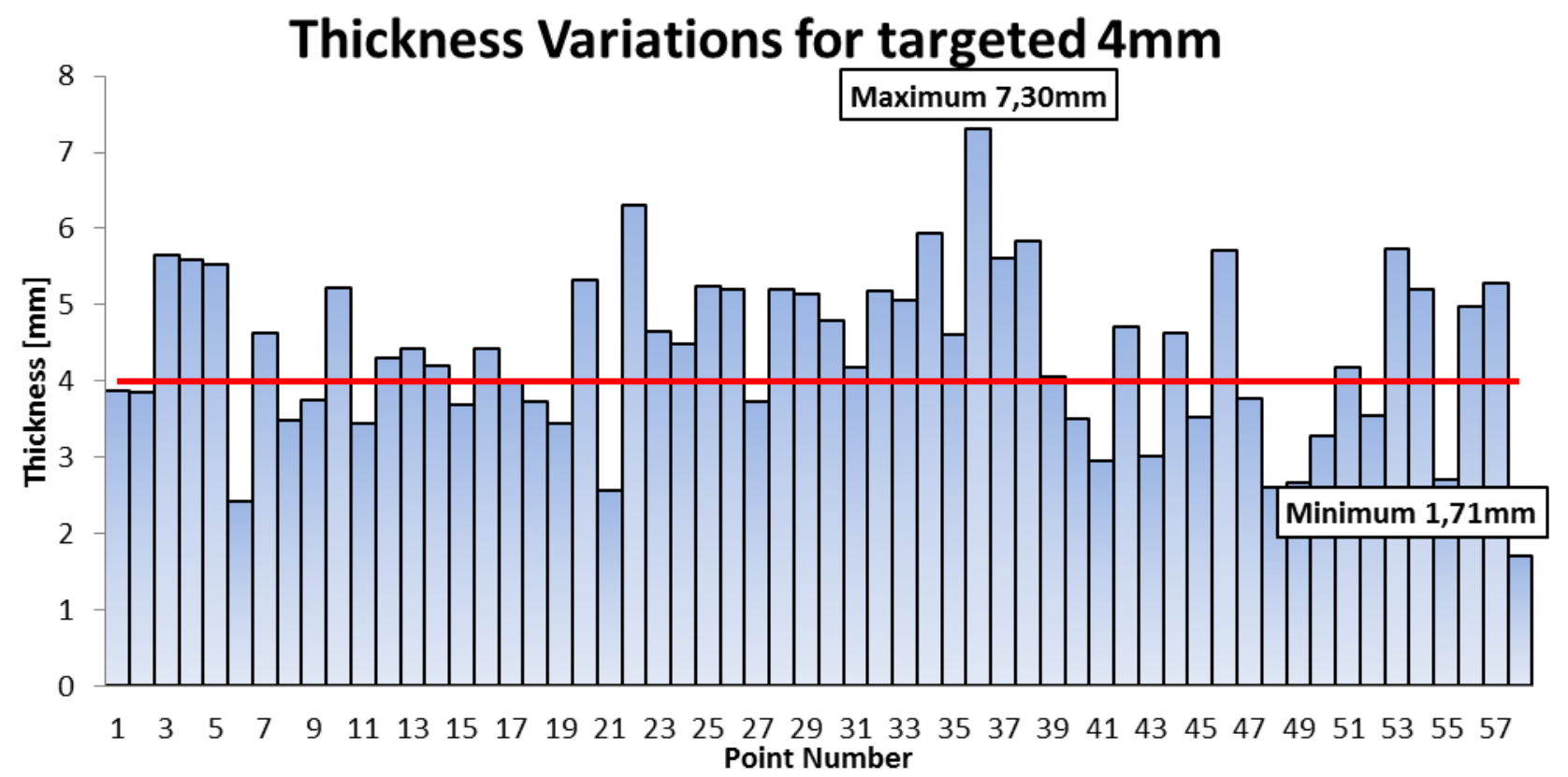

Figure 9 Thickness measurement variations for top coat with desired thickness $4 \mathrm{~mm}$ (BoegJensen 2013)

\subsection{Large scale pull test}

In an attempt to better understand the adhesion and toughness of the liner under actual operating mine conditions, a series of large scale pull tests were conducted on underground and blasted wall surfaces at MTI's test ramp site. This version of a test method described by Tannant (1997) and Espley (1999) sacrifices the repeatability of loading the liner indirectly behind a set of plain-surfaced, interlocking paving stones in favour of gaining some operational understanding of the impact of liner thickness variation on the baggage capacity of the liner only for a square bolting pattern of $1 \mathrm{~m}$. This particular series of tests were sprayed with the ABB robotic prototype, which also provided some clarification of the level of confidence with respect to coverage and thickness variation. The general test parameters were to spray a $2 \times 2 \mathrm{~m}$ patch onto the wall and bolt with a $1 \times 1 \mathrm{~m}$ grid, (Figure 10).

Due to the highly variable nature of this modified test method, the results show only the general characteristics of the $3 \mathrm{M}$ PCM system (with and without primers); the actual numerical results varied greatly if there was a thin spot in the liner, which typically occurred at the pull plate which was the highest stress point in the system. It was found that the 3M PCM system behaved like mesh based on its initial resistance to movement and elongation, but the initial resistance to load could be increased with a thicker application. Typical values for load and deflection based on $4 \mathrm{~mm}$ of $3 \mathrm{M}$ PCM were approximately $3 \mathrm{t}$ and $360 \mathrm{~mm}$ respectively; while $4 \mathrm{~mm}$ of $3 \mathrm{M} \mathrm{PCM}$ applied over fibre-reinforced shotcrete withstood $27 \mathrm{t}$ before reaching the load limit of the test ram. 
The MTI site was primarily chosen for the large scale pull test for evaluating 3M PCM primer alternatives, toughness and blast resilience performance, given a non-ideal surface roughness. In an earlier test series, Swan (2012), mesh was compared to double thickness liner, showing that the liner outperformed mesh at every displacement, but sustained more damage in doing so, Figure 10. By taking greater care to ensure better coverage and thickness control, together with the promise of increased adhesion, it was hoped to improve on this comparison. Finally, a test was planned to pull the top coat applied to a shotcreted surface but to not include the shotcrete itself.

Unfortunately, for various reasons, this second series of large scale pull tests proved a disappointment, providing little or no suggestion of anticipated improvements to top coat performance; incomplete measurement data and premature tearing failures of the liner in areas of poor coverage were the only results.

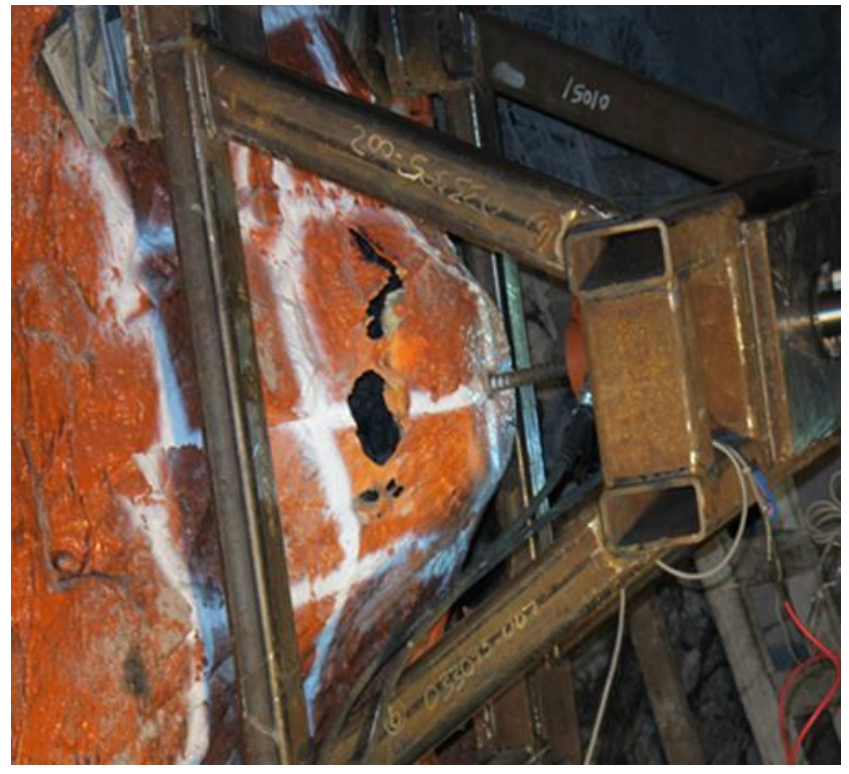

(a)

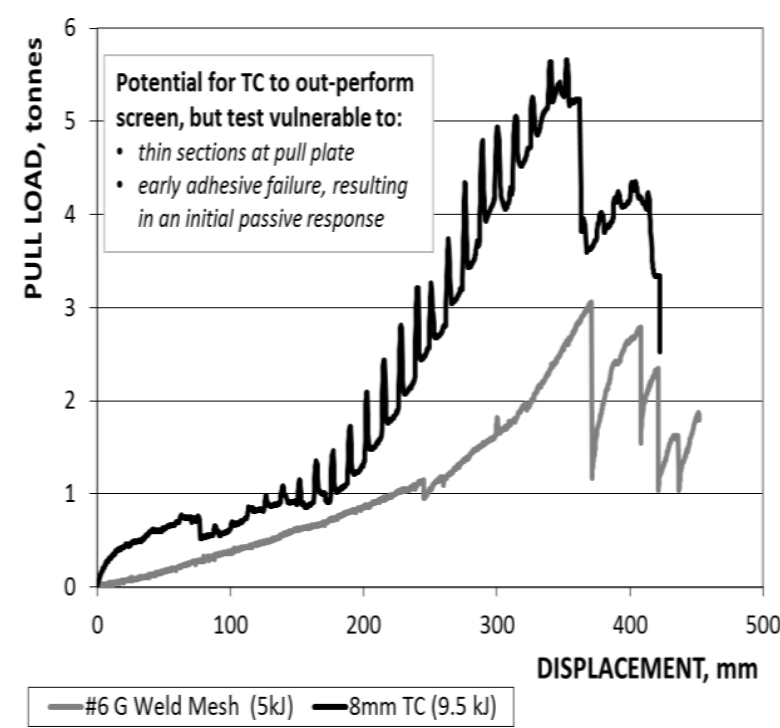

(b)

Figure 10 (a) typical top coat failure observed in the large scale pull test; (b) comparison between no. 6 gauge weld mesh and nominally $8 \mathrm{~mm}$ thick topcoat (Swan 2012)

\subsection{Round determinate panel}

To complement the in situ testing and to better define the contribution of $3 \mathrm{M} \mathrm{PCM}$ with a primer on shotcrete samples, several tests were conducted using the ASTM C1550 round determinate panel (RDP) test standard (Figure 12). Figure 11 shows the test set-up. A circular disk of cast fibre reinforced shotcrete was placed onto three rigid points and a ram loads used to the shotcrete at its centre. Several tests were conducted with different thicknesses, primers and cure ages. It was shown that using a primer did not meaningfully improve the results compared to 'no primer' tests, and that the 3M PCM top coat provided a reinforcing aspect to the shotcrete. The $3 \mathrm{M} \mathrm{PCM}$ increased the peak load of the shotcrete before cracking and subsequently carried the load across a displacement of approximately $140 \mathrm{~mm}$, which provided an increase in total toughness by as much as $400 \%$ over fibre-reinforced shotcrete only (Swan 2014). 

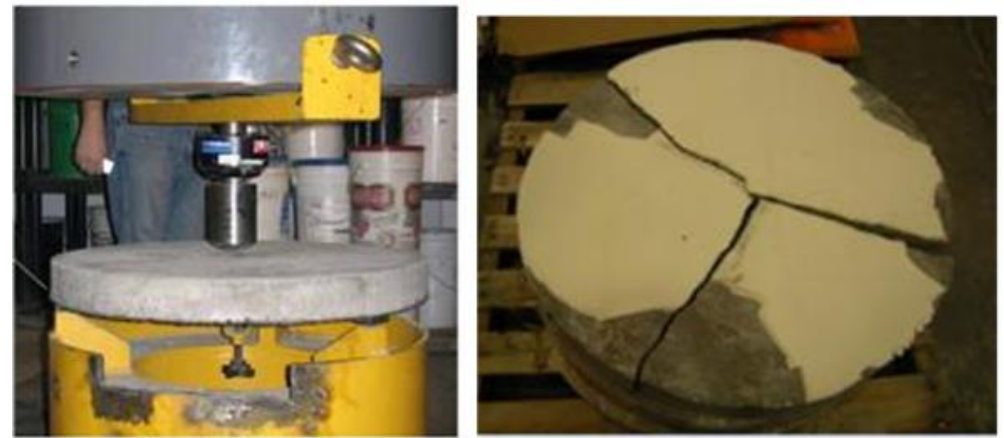

Figure 11 Round determinate panel test configuration and example of a failed sample coated with 3 M PCM

(Swan 2014)

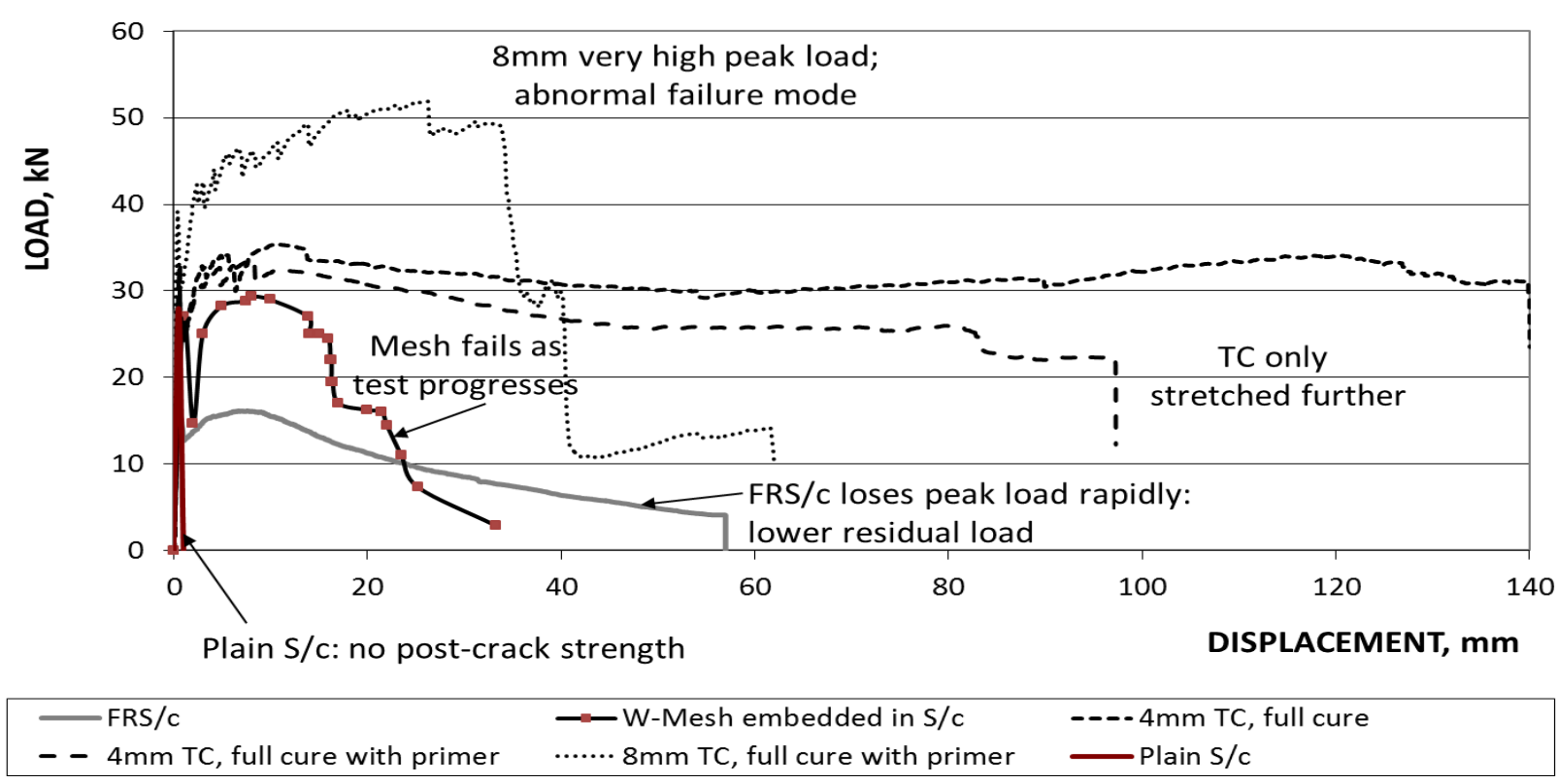

Figure 12 Summary of the round determinate panel test showing the general increase in toughness capacity afforded to shotcrete by the addition of the 3 M PCM (Swan 2014)

\section{Discussion and conclusions}

TSLs are directly attached to the rock surface, like a second skin. With initial deformation of the rock mass surface, on the order of millimetres, this attachment acts to provide some reinforcement effect. However, ultimately this TSL is designed to yield in tension and to retain failed rock, giving it good potential for use as part of a support system controlling deforming ground. It is currently understood that other key properties, such as pop-off - mode I tensile - and peel - mode III anti-plane - adhesive strength, tear strength and elongation, should be seen as trade-off properties to ensure that adhesion failure occurs rather than tensile/tearing failure of the liner itself. $3 \mathrm{M}^{\prime} \mathrm{s}$ PCM liner possesses the required material properties to withstand the significant stresses under different loading conditions. Furthermore, based upon laboratory evidence described elsewhere, Swan (2014), the PCM liner appears to have significant capability to flex and absorb dynamic energy. Given this, together with its self-extinguishing properties, the 3M PCM liner has met the original performance expectations and further confidence should be achievable with prolonged real world testing in full rounds.

Compared to shotcrete, TSL's typically require an order of magnitude less material volume, resulting in far less handling and delivery issues. However 3M's PCM should be compared with mesh. It was found through the large scale pull test that the $3 \mathrm{M}$ PCM system behaved closer to mesh based on its initial resistance to 
movement and elongation, but that this initial resistance to load could be increased with thicker applications. However, the strongest justification for PCM application, in terms of providing increased toughness performance, was found when $3 \mathrm{M} \mathrm{PCM}$ was applied directly over shotcrete as originally seen in the round determinate panel testing. The TSL surface is smoother than shotcrete or mesh and less likely to hold mine dust. They are also highly visible, leading to a brighter mine environment. Finally, they show good potential to significantly improve the capability of ground support systems at depth.

Extensive environmental testing conducted in field testing with 3M PCM suggest that isocyanates can be fully managed with the help of local ventilation control and robotic application. In addition proper personal protective equipment, detailed in the mine's safety protocol, must be used when entering the working area during application and for 30 minutes after application. The isocyanate level measurements showed that manageable concentrations of airborne isocyanates were present during spraying in the hot zone or immediate working area and dissipated within 30 minutes. This investigation allowed for a safety protocol to be set up: a physical barricade $20 \mathrm{~m}$ beyond the hot zone, during spraying and for 30 minutes afterwards together with having the local ventilation turned off during spraying and 30 minutes afterwards. These actions were shown to assure a safe working environment while the trials proceeded.

The robotic application controlled the thickness continuity to an acceptable level by providing constant speed and spray pressure during application. The sprays used a four pass pattern, however when the sprays flipped over they missed large sections of the perimeter of the applied area. Areas with reduced coverage were usually rare, occurring mainly in shadowed areas but even here some coverage was achieved. The coverage of the full composite was reduced since the foam primer pattern was wider than the topcoat pattern. To improve the coverage the robot was programmed to spray two horizontal patches and two vertical patches, back and forth with the nozzle angle of application alternately reversed. This resulted in better coverage since each point would be sprayed from four different angles. The coverage was improved with further programming, providing specific patches and by adjusting the spraying angles.

The operational challenges at this point are related to the peeling at the leading edges and the fly-rock damage due to the in cycle blast. It should be noted here that no perimeter controlled drilling was performed and the blasting agent was ammonium nitrate-fuel oil (ANFO). The most significant damage occurred where the full composite was applied, the severity of which was unexpected. Reasons for this could be related to the method of surface preparation not being to the intended protocol, and that the bolting pattern did not extend to the leading edge as would be done with wire mesh. Without the leading edge being bolted, the foam layer was too weak to withstand the blast damage without peeling back. The foam has low stiffness and relatively low density with some energy absorption capability. The fly-rock damage may be due to the soft layer of primer beneath the topcoat, making it more susceptible to puncturing. After the first impact the foam may loosen over an area, forming de-bonded sections of top coat, which could have made the top coat more prone to impact damage. The top coat requires about 72-96 $\mathrm{h}$ to achieve full strength. Prior to that the top coat is still curing and the toughness properties are being enhanced during the curing time. After 1-2 $\mathrm{h}$, the liner is ready for bolt installation and the curing process continues after bolting to reach the full strength. The time requirement to reach full strength does not compare favourably with that required to complete the bolting and face drilling cycles before blasting.

After the use of foam primer was abandoned and some of the tests were executed with the top coat only, the results immediately improved. The top coat had higher adhesion to the rock, decreasing the peeling and fly-rock damage. However whichever system is selected, the round determinate panel testing still showed that when 3M PCM was sprayed on top of shotcrete it increased the reinforcing capacities of shotcrete. This observation serves to demonstrate the importance of balancing or trading-off the laboratory/technical aspects of TSL performance with operational realities.

The results from the trials are based on the liner applied on the walls only. In order to make a fair geotechnical judgment on the liner's capability, it needs to be further investigated how the liner performs when applied on the shoulders and back in addition to the walls as this is how it would be applied in a real mining environment. Another task is to investigate a rehab procedure for damage caused to the liner. 
At this stage in its evolution the TSL itself has been shown to enhance the capacity of existing support systems, though given further development and proof, it may also be found to replace current liner support elements under certain ground conditions.

It is recognised that the liner has great potential. It is however not at this point ready to become a superior component in an underground rock support system. Full proof of operational liner function requires underground deployment of a prototype mobile carrier. The carrier should be able to place enough liner in a wide variety of ground conditions in active mining areas to demonstrate the benefit to development cycle times and long-term performance, thus completing the justification for full commercialisation. Although significant evidence was found so far, the engaged participants are not in a position to financially support a new to the world, prototype carrier to obtain full, functional proof of the value and functionality of the liner.

\section{Acknowledgement}

This paper was written at Luossavaara-Kiirunavaara AB (LKAB) in Kiruna and I thank LKAB for supporting me in its writing, both in permitting me time but also through the support I gained from my colleagues at Research and Development, Mining Technology.

\section{References}

Boeg-Jensen, P 2013, 'Managing the engineering, health \& safety aspects of Thin Spray-On Liner Application', Underground trials at Xstrata Nickel Sudbury Operations, Master's Thesis Natural Resource Engineering, Luleå University of Technology, Luleå.

Espley, SJ 1999, 'Thin spray-on-liner support \& implementation in the hard rock mining industry', Master's Thesis, Laurentian University, Sudbury.

Swan, G 2012, '3M TSL Large-Scale Pull test report: MTI Ramp Campaign, August-October, 2012', CAMIRO/DMRC technical report, November 2012

Swan, G 2014, 'Thin Spray-On Liner Project', Status Report \#2-November 2013, Deep Mining Research Consortium, Sudbury.

Tannant, DD 1997, 'Large-scale pull tests on Mineguard', technical report, INCO Mines' Research, Geomechanics Research Centre, Sudbury. 
